\title{
PRONOMES COMO DETERMINANTES: ALGUMAS PROPRIEDADES DO ELEMENTO INTERROGATIVO QUE EM PORTUGUÊS BRASILEIRO*
}

\author{
Deisi Cristina G. M. Vidor \\ Sérgio de Moura Menuzzi \\ Pontifícia Universidade Católica do Rio Grande do Sul
}

Resumo: Neste trabalho, temos como objetivo analisar as propriedades do elemento interrogativo que em estruturas frásicas do Português Brasileiro, tomando por base assunções minimalistas nos moldes de Chomsky $(1995,1998)$. Durante nossa análise, apresentaremos evidência adicional à análise proposta por Raposo (1998b) para a forma $o$ no Português Europeu, o que culminará na extensão da análise desse autor para a discussão do fenômeno por nós investigado. Assumindo a idéia de que pronomes são determinantes, mostraremos que a forma interrogativa que apresenta-se distribuída em Português Brasileiro ora como determinante interrogativo, ora como pronome interrogativo. Além disso, formularemos, dentro do programa minimalista, mais uma condição que se faz necessária para dar conta das propriedades do elemento interrogativo que, nomeadamente NO DELAY.

Palavras-chave: Elemento interrogativo que; programa minimalista; condições de economia

\section{Introdução}

As formas átonas $o, a, o s$, as do Português Europeu [PE] (bem como na modalidade escrita do Português culto do Brasil) podem ser usadas em três contextos sintáticos diferentes, e, para cada um destes contextos, a gramática tradicional oferece um termo específico para caracterizá-las; isto é ilustrado em $(1 \mathrm{a}, \mathrm{b}, \mathrm{c})$ abaixo (com a forma $o$, o que se fará em todo este trabalho; no que segue, usamos o termo "a forma $o$ " para nos referirmos a toda a classe destes elementos):

Gostaríamos de agradecer à Profa. Leda Bisol e ao Prof. Carlos Mioto pelos comentários feitos à versão inicial deste squib. Quaisquer incorreções ou imprecisões remanescentes são de nossa inteira responsabilidade. 
(1) a. Artigo definido:

Gostei de quase todos os veículos, mas só compraria [o carro vermelho].

b. Pronome demonstrativo:

Gostei de quase todos os carros, mas só compraria [o vermelho].

c. Pronome pessoal:

Gostei do carro vermelho, mas não $o$ compraria.

Evidentemente, esta classificação tradicional implica a existência de três formas distintas que são, no entanto, homófonas. Recentemente, Raposo (1998b) propôs, entretanto, uma análise unificada da forma $o$ baseada, de um lado, (i) na hipótese de Postal (1966) de que pronomes pertencem, na verdade, à categoria sintática dos determinantes, e, de outro, (ii) numa certa formulação específica das condições de economia de derivação do aparato minimalista de análise (CHOMSKY, 1995).

O objetivo deste squib é fornecer evidência adicional para a análise de Raposo da forma o, demonstrando que pode ser naturalmente estendida para outra forma do português, a forma interrogativa que, cuja distribuição é ilustrada em $(2 \mathrm{a}, \mathrm{b})$ :

(2) a. Determinante interrogativo:

O Paulo teria tomado [que atitude] numa situação destas?

[Que atitude] o Paulo teria tomado numa situação destas?

b Pronome interrogativo

Que teria o Paulo feito numa situação destas?

Estaremos considerando as propriedades desta forma tal como se manifestam em nosso dialeto, a que passaremos a chamar de Português do Brasil $[\mathrm{PB}]^{1}$, embora acreditemos que muito das observações que fazemos e da análise que propomos sejam facilmente extensíveis ao uso de que em outros dialetos (cf. nota 10 abaixo).

Para sermos específicos, nosso dialeto é o que se pode chamar de variedade gaúcha do Português culto em sua modalidade falada: é falado na capital gaúcha, Porto Alegre, por indivíduos com escolaridade universitária. 
O squib está organizado do seguinte modo: na seção 2, procuramos tornar explícitas as premissas fundamentais da análise de Raposo relevantes à presente discussão; isso inclui, como veremos, a formulação de uma condição adicional (NO DELAY) não adotada explicitamente por Raposo. $\mathrm{Na}$ seção 3, demonstramos como 0 aparato desenvolvido permite uma explicação elegante das propriedades da forma que em $\mathrm{PB}$; em particular, mostramos que estas propriedades sugerem que NO DELAY é, de fato, uma condição necessária. Finalmente, na seção 4, apontamos brevemente alguns problemas empíricos que surgem com a análise que propomos, e algumas questões teóricas postas pela condição NO DELAY.

2. A análise de Raposo (1998b) da forma “ $O$ "

Como dissemos, um dos componentes básicos da análise de Raposo é a hipótese de Postal de que pronomes são, na verdade, determinantes; especificamente, Raposo propõe que a forma $o$ é sempre um determinante, inclusive em seus usos "pronominais" (cf. $(1 b, c)$ acima). De acordo com esta hipótese geral, Raposo postula as seguintes representações sintáticas para os três contextos ilustrados em (1) ${ }^{2}$ :

(3) a...., mas só compraria [DP [DET $o$ ] [NP carro vermelho]] [art.def.]

b...., mas só compraria [DP [DET $o$ ] [NP [N pro ] vermelho]] [pron.dem.]

c...., mas não [DET $o]_{\mathrm{i}}$-compraria [DP [DET $\left.\mathrm{t}_{\mathrm{i}}\right]$ [NP [N pro $\left.\left.]\right]\right]$ [pron.pessoal]

Como (3a) ilustra, a forma $o$, usada como artigo definido, é um determinante que toma como complemento um NP que possui conteúdo fonético. De acordo com ( $3 \mathrm{~b}$ ), o uso da forma $o$ como um pronome demonstrativo é essencialmente análogo a seu uso como artigo definido: também é um determinante que toma como complemento um NP com conteúdo fonético. A diferença entre (3a) e

2 As estruturas em (3) abreviam as representações sintáticas das frases no momento em que SPELL-OUT se aplica. Por razões de espaço, não faremos qualquer esforço para apresentar aqui os conceitos básicos do modelo minimalista; para uma introdução breve, ver Raposo (1998a). 
(3b) é que, em (3a), o $N$ núcleo do NP tem conteúdo fonético, enquanto que, em (3b), o $\mathrm{N}$ núcleo é uma categoria vazia, pro.

Finalmente, (3c) difere de (3a,b) em dois aspectos: (i) o NP complemento do DET não possui conteúdo fonético; e (ii) a forma $o$ se move para fora do DP e se cliticiza ao verbo (à esquerda, i. é, se procliticiza). ${ }^{3}$ Evidentemente, o problema principal para uma análise unificada da forma reside justamente nestas diferenças entre (3c) e (3a,b); o que Raposo procura mostrar, entretanto, é que tais diferenças podem ser deduzidas naturalmente da hipótese de que o é um determinante, em conjunção com os mecanismos postos à disposição pela teoria minimalista. Vejamos, pois, como procede sua análise.

Em primeiro lugar, é preciso explicar por que $o$ tem de se mover para a esquerda do verbo e se procliticizar a ele, ao invés de permanecer in situ e se encliticizar:

(3) d.. ..., *mas não compraria-[Dp $O$ [NP [N pro ]]]

De acordo com Raposo, isso deriva de uma propriedade lexical adicional da forma $o$ : além de pertencer à categoria sintática dos determinantes, pertence à categoria morfo-fonológica dos proclíticos (ver, entretanto, a nota 3 acima). Isso significa que deve se prender à esquerda de uma palavra acentuada (uma palavra prosódica), ou a estrutura resultante não satisfará as condições de interpretação

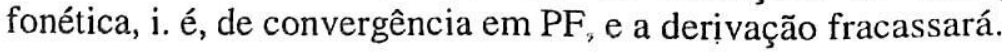

As estruturas em ( $3 \mathrm{a}, \mathrm{b})$ convergem em PF sem necessidade de movimento de $o$ porque há uma palavra acentuada à direita de $O$ dentro do DP, seu domínio prosódico ${ }^{4}$ : em (3a), esta palavra é o $\mathrm{N}$

3 Na verdade, esta descrição preliminar é uma simplificação dos fatos do $\mathrm{PE}$, e serve apenas para Raposo introduzir os elementos básicos de sua análise. É óbvio, por exemplo, que pronomes átonos podem aparecer como elementos enclíticos em $\mathrm{PE}$ e, muito possivelmente, são formas enclíticas mesmo quando antepostas ao verbo flexionado (CARVALHO, 1989). Estas e outras qualificações requerem complicações na análise de Raposo, mas pouco afetam o que temos a dizer neste squib. Por isso, limitamo-nos às considerações elementares acima.

Raposo observa que não basta haver uma palavra prosódica à direita de $o$; esta palavra deve fazer parte do mesmo domínio prosódico imediato, ou a 
núcleo de NP, e, em (3b), é o modificador vermelho. Se o permanecesse in situ em (3c), entretanto, não haveria palavra acentuada à sua direita à qual se procliticizar, e a estrutura não convergiria em PF; daí a inaceitabilidade de (3d). Portanto, movimento de $o$ para a esquerda do verbo em (3c) é uma operação de último recurso, necessária para a convergência da derivação em PF.

Entretanto, Raposo observa que o fato de $o$ ser proclítico não é suficiente para determinar sua distribuição como "pronome pessoal". A razão disso é que não é qualquer palavra à esquerda de $o$ que pode hospedá-lo: em PE, esta palavra tem que ser o verbo portador das marcas de tempo/modo:

4) a. O Paulo não havia lido recentemente [o jornal de Lisboa]

b. *O Paulo não havia lido $o$-recentemente $\left[t_{i}\right.$ pro $]$

c. *O Paulo não havia $o$-lido recentemente $\left[t_{i}\right.$ pro $]$

d. O Paulo não $o$-havia lido recentemente $\left[\mathrm{t}_{\mathrm{i}}\right.$ pro $]$

Para explicar a inaceitabilidade de $(4 b, c)$, Raposo recorre, então, a algumas das hipóteses básicas do modelo minimalista.

Uma destas hipóteses é a que fundamenta as versões mais recentes da teoria minimalista do Caso (CHOMSKY, 1998): Caso é um traço formal de determinantes e deve ser checado por meio de uma relação estrutural apropriada com um núcleo funcional que tenha especificação compatível. Presumivelmente, este núcleo em $\mathrm{PE}$ deve ser aquele ocupado pelo verbo portando as marcas de tempo/modo no momento em que a operação de SPELL-OUT se aplica à derivação, pois é para este núcleo que $o$ se move (cf. (4d)); concretamente, Raposo propõe que este núcleo seja T (i.é, Tempo).

Note que o traço que deve ser checado por $o$ em $\mathrm{T}$ deve ser fraco, ou esta forma teria de mover-se mesmo quando seguida à direita

procliticização é bloqueada. Daí por que uma estrutura como (i) abaixo é excluída:

(i)..., mas só compraria [DP [DET $o$ ] [NP [N pro ]]] [PP à Maria ]

Presumivelmente, o PP não pertence ao mesmo domínio prosódico que $o$ e, portanto, não pode hospedá-lo fonologicamente. Não
discutiremos aqui o que define um domínio prosódico, para o que remetemos o leitor ao trabalho de Raposo e às referências lá citadas. 
por uma palavra acentuada em seu domínio prosódico, como em (4a). Se o traço fosse forte, deveria ser checado antes da derivação dar entrada em PF, em que traços fortes não são interpretáveis e levam a derivação a fracassar; neste caso, a estrutura de uma frase com a numeração de (4a) deveria ser, no momento de aplicação de SPELLOUT, algo como (5) abaixo, o que evidentemente não é corretos:

(5) *O Paulo não [T $\left[\mathrm{T} o_{i}\right.$-havia $]$ lido recentemente [DP $t_{i}$ jornal de Lisboa ] ]

Assim, embora a forma $o$ deva eventualmente mover-se para $\mathrm{T}$ para checar seu traço de Caso, isso só acontece depois da aplicação de SPELL-OUT, já que: (i) movimento de $o$ para T não é exigido por seu traço de Caso, que é fraco, e (ii) também não é exigido para convergência em PF, já que $o$ satisfaz in situ seus requisitos de convergência em PF (lembre-se de que ele precisa procliticizar-se a uma palavra acentuada dentro de seu domínio prosódico, o que pode ser feito dentro do DP em (4a)). E, se o movimento de $o$ não é exigido para convergência antes de SPELL-OUT, então ele deve se aplicar depois de SPELL-OUT devido a uma das condições minimalistas de economia, PROCRASTINATE: movimento pré-SPELL-OUT é mais custoso do que movimento pós-SPELL-OUT.

Reconsideremos agora o uso de $o$ como pronome pessoal, em particular, no que diz respeito às restrições sobre seu movimento, ilustradas em (4b,c,d), que repetimos em $(6 a, b, c)$ abaixo, respectivamente:

(6) a. *O Paulo não havia lido $o$-recentemente

5 Note que não é necessário o pied piping do material fonético contido dentro do DP, já que, por hipótese, a forma $o$ pode satisfazer seus requisitos de convergência em PF por meio da procliticização ao verbo em T. De acordo com a teoria da checagem de traços de Chomsky (1995, 1998), movimento é, no caso ótimo, movimento apenas dos traços formais; movimento de material fonético é sempre resultado de pied piping, já que não é possível movimentar traços formais pré-SPELL-OUT sem que este movimento não tenha reflexo em PF. Pied-piping é, entretanto, uma operação de último recurso e deve ser minimizada sempre que possível. Daí o porquê de o movimento de constituintes ser, $\mathrm{cm}$ geral, limitado ao constituinte mínimo contendo o traço que deve ser checado. No caso de (6), este constituinte mínimo é a forma $o$ ela mesma. 
b.*O Paulo não havia $o$-lido recentemente

c. O Paulo não $o$-havia lido recentemente

Como vimos acima, para Raposo, a estrutura gramatical é aquela em que $o$ antecipa para antes da aplicação de SPELL-OUT o movimento para $T$ exigido para checagem do traço de Caso: o resultado é uma estrutura convergente em PF, (6c). Para entender, entretanto, por que esta é a única opção gramatical, e por que opções de movimento, como as ilustradas em $(6 \mathrm{a}, \mathrm{b})$, são excluídas, é necessário que tornemos explícitas algumas premissas implícitas no raciocínio de Raposo (tal como exposto em Raposo, 1998a, ao menos).

Considere (6a): por que esta estrutura é excluída? Evidentemente, a PF resultante é convergente, já que $o$ está procliticizado a uma palavra acentuada que, presumivelmente, está em seu domínio prosódico, supondo que $o$ está adjungido a recentemente. Suponha, entretanto, que a adjunção de $o$ tenha se dado na sintaxe pré-SPELLOUT. Portanto, pré-SPELL-OUT a forma $o$ sofre uma operação de movimento que a adjunge a recentemente, como ilustrado em (7a) abaixo; entretanto, os traços formais da forma $o$ ainda precisam ser checados em T, com o que é preciso, no trecho pós-SPELL-OUT da derivação, aplicar-se ainda as operações de movimento necessárias para levar os traços formais de $o$ até T, como em (7b) (lembre-se de que pied piping de material fonético é requerido só nas operações préSPELL-OUT, cf. nota 5 acima):toaqui

(7) a. Pré-SPELL-OUT:

O Paulo não havia lido $o_{[+\mathrm{Caso}, . . .}$-recentemente [DP $t$ pro ]

b. Pós-SPELL-OUT:

O Paulo não $[\mathrm{T}[+$ Caso, ...] havia] lido $o$-recentemente [DP $t$ pro ]

Na derivação resumida acima, que chamaremos de derivação indireta, além dos passos necessários para a execução do movimento de $o$ até T (executados pós-SPELL-OUT), haveria, pelo menos, um passo a mais em relação a uma derivação que leva $o$ diretamente a $T$ (p.ex., (6c)): o passo que adjunge $o$ a recentemente:

(8) a. Derivação Indireta:

O Paulo não $[\mathrm{T}[+\mathrm{Caso}, . .$.$] havia] lido o$-recentemente [DP $t$ pro ]

2 movimentos: pós-SPELL-OUT pré-SPELL-OUT 
b. Derivação Direta:

O Paulo não [T $o_{[+\mathrm{Caso}, . . .]}$-havia] lido recentemente [DP ${ }^{t}$ pro ]

Note agora que uma das condições minimalistas de economia, a "Shortest Derivation Condition" [SDC, "condição da derivação mais curta"], requer que se minimize o número de operações necessárias para convergência. Mas, como acabamos de ver, a derivação indireta envolvida em (6a)-(8a) requer uma operação a mais que uma derivação direta (como em (6c)-(8b)); a derivação indireta é, portanto, excluída pela SDC. Isto expressa formalmente a intuição de Raposo, segundo a qual o movimento de $o$ para convergência em PF é um "movimento preguiçoso", i.é, apenas antecipa uma operação independentemente necessária: qualquer derivação que recorra a um movimento que não é independentemente requerido para fins de checagem de traços vai necessariamente ter passos adicionais e, portanto, vai violar a SDC 6 .

Quanto à (6b), (*O Paulo não havia o-lido recentemente), há duas possibilidades a considerar, em princípio: (i) o movimento que deve levar $o$ até $\mathrm{T}$ não pode se dar em apenas um passo, mas é "cíclico", i.é, o (ou seus traços formais, em caso de movimento em FL) deve passar pela posição intermediária que contém o verbo principal, lido; ou (ii) o movimento de $o$ a $\mathrm{T}$ não é cíclico e pode se

6 Para fins de ilustração, considere uma outra derivação possível para (6a): a adjunção dos traços fonéticos de $o$ a recentemente é uma operação pósSPELL-OUT no ramo da derivação que leva a $P F$; no ramo que leva a LF, os traços formais de $o$ sofrem as operações de movimento necessárias para serem checados em T. Chamemos esta derivação de "derivação por PF". Chamemos a derivação que leva simultaneamente os traços fonéticos e formais de $o$ a T, como em (6c), de "derivação direta". Note agora que na derivação direta são necessárias exatamente as mesmas operações que são necessárias na derivação por PF para levar os traços formais de $o$ até T. Portanto, a derivação por PF exige, pelo menos, uma operação a mais que a derivação direta - a operação que adjunge os traços fonéticos de $o$ a recentemente em PF. Conseqüentemente, a derivação por $\mathrm{PF}$ de (6a) também é excluída pela SDC. 
dar em apenas um passo, sem necessidade de um pouso intermediário junto à posição que contém o verbo principal ${ }^{7}$. Se a possibilidade descrita em (ii) é correta, (6b) é obviamente excluída pela SDC: a derivação em (6b) incluiria um pouso intermediário não exigido por razões independentes, i.é, uma operação de movimento além das necessárias para levar os traços formais de $o$ até T. Por outro lado, se a possibilidade descrita em (i) acima for correta, i.é, se movimento de $o$ é cíclico e passa por posições intermediárias em seu caminho para $\mathrm{T}$, então algumas complicações são necessárias para que a análise de Raposo se mantenha. Consideremos, pois, este caso.

Note que a derivação representada por (6b) só exige, préSPELL-OUT, as operações de movimento necessárias para que a estrutura convirja em PF: as operações necessárias para levar $o$ até a primeira palavra acentıada a que se possa procliticizar. Suponha que estas operações fossem independentemente necessárias (i.e., que movimento de $o$ é "cíclico"). Todas as demais operações necessárias para a eventual checagem dos traços (remanescentes?) de $o$ seriam adiadas para o trecho da derivação pós-SPELL-OUT, i.é, uma tal derivação faria as operações mínimas para fins de convergência em PF, como exige PROCRASTINATE. Portanto, a derivação representada por (6b) não é excluída nem pela SDC, nem por PROCRASTINATE. O que a exclui, então?

Suponhamos que o movimento de $o$ seja "cíclico". Neste caso, o que o contraste entre (6b) e (6c) aparentemente indica é o seguinte: se $o$ é obrigado a se mover antes de SPELL-OUT (p.ex., para satisfazer seus requisitos de convergência em PF), então, a cadeia pré-SPELLOUT resultante deve ser a cadeia máxima de $o$, i.é, $o$ deve chegar até a posição final do movimento necessário para chegar seus traços formais, que é $\mathrm{T}$. Ou seja, tem-se neste caso o efeito contrário a PROCRASTINATE: uma vez que uma operação de movimento em uma cadeia se faz necessária, a cadeia não pode adiar suas demais

7 Raposo não discute explicitamente se o pouso intermediário é necessário ou não em caso de movimento pré-SPELL-OUT de $o$, bem como não discute como seria a derivação no caso de estruturas com verbos auxiliares, como em (6). Daí o motivo pelo qual devemos considerar ambas as possibilidades. 
operações de movimento. A fim de não nos alongarmos na discussão sobre se as condições de economia minimalistas são ou não capazes de derivar este efeito, presumiremos aqui simplesmente que ele resulta de uma condição primitiva, que chamaremos de NO DELAY.

Assim, supondo que o movimento de $o$ seja cíclico, somos levados à conclusão de que uma condição adicional, NO DELAY, é necessária para excluir a derivação ilustrada em $(6 \mathrm{~b})^{8}$. Como veremos a seguir, NO DELAY parece necessária para dar conta das propriedades do elemento interrogativo que e, portanto, tem alguma motivação independente.

Resumamos, então, a discussão precedente: a análise unificada que Raposo propõe para as diversas ocorrências da forma $o$ em PE postula, de um lado, a caracterização em (9) das propriedades lexicais de $o$, e, de outro, se apóia nas hipóteses minimalistas em (10):

(9) As formas $o, a, o s$, as em PE possuem as seguintes propriedades lexicais:

a. pertencem à categoria sintática dos determinantes;

b. à categoria morfo-fonologica dos proclíticos;

c. e possuem traço formal de Caso fraco.

(10) a.DPs objetos checam seus traços de Caso em T;

8 Na verdade, há um problema com a análise baseada em NO DELAY que acabamos de sugerir. Assim como a derivação ilustrada em (6b) viola NO DELAY, vimos também que derivação em (6c) viola PROCRASTINATE (na interpretação em que 0 movimento de $o$ requer um passo intermediário). Ora, se ambas as derivações violam uma condição, por que somente a que viola NO DELAY é excluída? Se ambas as condições são de economia, então teríamos de exigir prioridade para NO DELAY. Outra possibilidade é que NO DELAY é uma condição para convergência, do que seguiria naturalmente sua prioridade sobre PROCRASTINATE. Esta possibilidade, entretanto, não tem apelo conceitual, já que NO DELAY e PROCRASTINATE formam um "par natural": "Adie a formação de cadeia para PF, se puder; mas, uma vez iniciada uma cadeia, vá até o fim". Isto sugere que NO DELAY e PROCRASTINATE são "faces" de uma única condição de economia. Evidentemente, estas são questões sobre a natureza de NO DELAY que não podemos discutir em detalhe aqui. 
INTERROGATIVO QUEEM PORTUGUÊS BRASILEIRO

b. PROCRASTINATE: operações de movimento devem ser adiadas para depois da aplicação de SPELL-OUT, se não forem necessárias para convergência em PF;

c. "Shortest Derivation Condition" [SDC]: o número de operações necessárias para convergência deve ser minimizado;

Finalmente, vimos que, no caso da derivação de (6c) acima exigir uma operação de movimento intermediária (em que $o$ pousa na posição ocupada pelo verbo principal, como em (6b)), a análise de Raposo precisará ser complementada por uma restrição adicional, a que chamamos de NO DELAY:

(10) d.NO DELAY: se uma operação de movimento é necessária para convergência em PF, então a cadeia máxima a que pertence deve ser realizada pré-SPELL-OUT.

$\mathrm{Na}$ próxima seção, passamos a investigar as propriedades do elemento interrogativo que em $\mathrm{PB}$ à luz da análise proposta por Raposo para a forma $o$ em $\mathrm{PE}$, com as possíveis revisões que sugerimos acima.

\section{Algumas propriedades do elemento interrogativo QUE em $\mathbf{P B}$}

Comecemos por observar que a extensão da análise de Raposo ao elemento que em PB tem um óbvio apelo inicial: que em $\mathrm{PB}$, assim como $o$ em PE, é usado tanto como um pronome (interrogativo neste caso), cf. (11a), quanto como um determinante (interrogativo), cf. (11b):

(11) a.Pronome:

Que fez o João pra agradar a Maria?

b. Determinante:

[Que tipo de coisa] o João faz pra agradar a Maria?

Ora, do mesmo modo que a identidade do artigo definido $o$ com o pronome pessoal $o$ sugere uma análise unificada destas duas ocorrências sintáticas, a identidade das duas ocorrências de que em (11) também, em princípio, seria mais elegantemente explicada se também pudéssemos analisá-las de modo unificado. A fim de demonstrar que esta análise é possível, passamos a considerar mais detalhadamente as propriedades de que em contextos como $(11 \mathrm{a}, \mathrm{b})$. 
Em (11b), que é coloquialmente pronunciado [ki] por razões bem conhecidas da literatura sobre a fonologia do PB: o contraste /e/ vs. /i/ é neutralizado em favor de /i/ em fim átono de um vocábulo formal (MATTOSO, 1970, entre muitos outros); este é, evidentemente, o contexto que caracteriza o uso clítico de que (11b). Em (11a), que pode ser pronunciado como um [ki] átono, proclítico a $f e z$, ou como [kê] tônico, em que é prosodicamente independente do verbo: p.ex., quando pronunciado como [ki] átono, que em (11a) não permite que material fonético seja inserido entre ele e o verbo (cf. (12a)); esta restrição não precisa ser observada se que é pronunciado como [kê] tônico (cf. (12b) $)^{9}$ :

a. *[ki] freqüentemente faz o João pra agradar a Maria?

b. [kê] freqüientemente faz o João pra agradar a Maria?

É preciso, portanto, inicialmente distinguir dois tipos de ocorrências de que pronominal: que pronunciado como a forma átona, clítica, [ki], e que pronunciado tonicamente [kê]. (Passaremos a indicar o elemento a que [ki] se cliticiza ou deveria se cliticizar por meio de um hífen ligando-o a palavra que o hospeda, p.ex.: “[ki]-faz o João aqui?”)

Há outra diferença notável entre [ki] e [kê]: somente o último pode ocorrer como um sintagma WH in situ, uma possibilidade disponível para interrogativas diretas no dialeto do $\mathrm{PB}$ de que tratamos aqui (esta observação foi feita originalmente em MENUZZI, 1994):

9 Na verdade, muitos falantes, incluindo a nós mesmos, acham estranho o uso de que tônico como pronome interrogativo, i.é, de [kê] no contexto (12b) e nos demais contextos discutidos abaixo; para cstes falantes, a única forma alternativa a [ki] nestes contextos é a perifrástica o que, pronunciada [ukê] (cf., p.ex., MENUZZI, 1994). É possível que [kê] scja uma forma fonologicamente reduzida de [ukê], um problema para investigação futura. Por outro lado, a Profa. Leda Bisol nos diz (cm comunicação pessoal) que, em muitos dialetos, as formas [ke] e [ki] estão em variação livre, podendo ser ambas pronunciadas tônica ou atonamente. Para tais dialetos, imaginamos que a distinção relevante seja, simplesmente, entre forma tônica e forma átona. Assim, daqui por diante, estaremos considerando [ki] como uma representação da pronúncia átona de que, e [kê] como uma representação da pronúncia tônica de que, independentemente da realização fonética da vogal. 
(13) A: O Paulo e a Maria trabalham juntos no projeto. A Maria é responsável pela transcrição dos dados ...

a B: E o João faz [kê]?

b. B:*E o João faz-[ki]?

A possibilidade de usar [kê] in situ é não problemática: sintaticamente, nada requer seu movimento (já que elementos WH in situ são permitidos em PB); morfo-fonologicamente, [kê] é, como vimos, um elemento independente; portanto, não precisa ocupar uma posição específica com relação a uma palavra acentuada. Considere agora (13b); mais especificamente, compare a impossibilidade de encliticizar [ki] a faz neste contexto com a possibilidade de procliticizá-lo a faz em (11a): o par mínimo é repetido em (14a,b):

(14) a. [ki]-faz o João para agradar a Maria?

$$
\begin{aligned}
& (=(11 \mathrm{a})) \\
& (=(13 b))
\end{aligned}
$$$$
\text { b.... *E o João faz-[ki]? }
$$

O contraste entre (14a) e (14b) sugere que [ki] é, como $o$ em $\mathrm{PE}$, um elemento proclítico, i.é, deve se prender à esquerda de uma palavra acentuada (um verbo, cf. (14a) versus (12a)). Entretanto, esta restrição morfo-fonológica não é suficiente para dar conta da distribuição de [ki]: embora ela seja igualmente satisfeita em (14a), repetida abaixo como (15a) e (15b), somente (15a) é aceitável; o mesmo contraste é ilustrado pelo paradigma em $(16)^{10}$ :

$$
\begin{aligned}
& \text { a .[ki]-faz o João para agradar a Maria? } \\
& \text { b. *O João [ki]-faz para agradar a Maria? }
\end{aligned}
$$

10 A obrigatoriedade da inversão sujeito-verbo flexionado em contextos como (15) e (16) foi originalmente observada com respeito à forma que em PE por Ambar (1992). Sua análise deste fato, entretanto, levanta sérios problemas (ver MENUZZI, 1994 para discussão). A maior parte das observações descritivas que fazemos na presente seção valem também para a forma que interrogativa do PE, do que concluímos que a análise que aqui proporemos pode ser a ela estendida.

À guisa de esclarecimento, deve-se notar que (15b) e (16b) são aceitáveis se há pausa entonacional entre João e [ki]: neste caso, João é plausivelmente um elemento topicalizado, e a estrutura é irrelevante para a discussão. Ver nota 11 a seguir. 
(16) a. [ki]-teria o João feito numa situação destas?

b. *O João [ki]-teria feito numa situação destas?

A pergunta é: qual a razão destes contrastes? Por que não basta procliticizar [ki] a uma palavra verbal, sendo também necessária a inversão de ordem entre o sujeito e o verbo flexionado?

Suponhamos que, tal como a forma $o$ em PE, [ki] em PB seja um determinante proclítico e que possa ser introduzido nos mesmos contextos sintáticos, i.é, como DET em (17a) ou (17b):

(17) a. "Pronome": ... [vp ...V [DP DET [NP [N pro ] ] ]

b. "Determinante".... [vP...V [DP DET [NP X ... ] ] ], em que $\mathrm{X}$ é um constituinte com conteúdo fonético.

Note agora que, tal como a forma $o$ em PE, sendo [ki] um determinante, deve conter um traço formal de Caso a ser checado em T; além disso, [ki] é um elemento interrogativo do tipo WH, i.é, é especificado pelo traço formal [+WH], que deve ser checado com um COMP interrogativo. Obviamente, ambos os traços são fracos, já que [ki] pode permanecer in situ quando ocorre no contexto (17b), confira:

(18) a. O João faz [DP [ki]-tipo de coisa] pra agradar a Maria?

b. *[ki]-faz o João [DP $t$ tipo de coisa] pra agradar a Maria?

Observe também que não apenas o movimento em (18b) não é necessário para a checagem pré-SPELL-OUT do traço [+WH] de [ki], que é fraco, mas também não é necessário para que [ki] satisfaça seus requisitos prosódicos: em (18b), há material à direita de [ki] que está dentro de seu domínio prosódico; portanto, [ki] pode procliticizar-se sem movimento. Como o movimento de [ki] em (18) não é necessário para a convergência da PF correspondente (cf. (18a)), PROCRASTINATE exclui a derivação em (18b) (do mesmo modo que exclui o movimento de $o$ em (5) acima).

Consideremos agora a ocorrência de [ki] em (17a): a ausência de material fonético dentro do NP à sua direita obriga [ki] a mover-se a fim de procliticizar-se e assim satisfazer seus requisitos prosódicos de convergência em PF. Portanto, movimento para a direita de um hospedeiro potencial, resultando em ênclise, como em (14b) acima (*E o João faz-[ki]?), não converge em PF. Por outro lado, 
movimento para um hospedeiro com o qual [ki] não checa traços, como em (12a) (*[ki]-frequentemente faz o João?), também não resulta em uma estrutura bem-formada, neste caso por razões de economia: como vimos na discussão do caso correspondente envolvendo a forma $o$ em PE, (6a) acima, tais derivações exigem pelo menos uma operação de movimento a mais além de todas as que são independentemente necessárias para checar os traços do elemento que se move (o movimento deste elemento para o hospedeiro). Por isso, tais operações são excluídas pela SDC.

Os casos mais interessantes, entretanto, são os contrastes em (15) e (16) acima, que repetimos abaixo como (19) e (20), respectivamente:

(19) a. [ki]-faz o João para agradar a Maria?

b. *O João [ki]-faz para agradar a Maria?

(20) a. [ki]-teria o João feito numa situação destas?

b. *O João [ki]-teria feito numa situação destas?

As perguntas cruciais são: por que não é suficiente que [ki] se procliticize a seu hospedeiro para que a estrutura seja bem-formada? Por que, além disso, é necessário que haja inversão entre verbo flexionado e sujeito? Presumindo, com Ambar (1992), que as inversões em (19)-(20) são casos de movimento de [V+T] para COMP, pode-se reformular estas perguntas nos seguintes termos: por que é necessário que [ki] se procliticize a $[\mathrm{V}+\mathrm{T}]$ em COMP?

Suponha que se adotasse a sugestão inicial de Raposo, de que a única exigência sobre a operação de movimento para convergência em PF é a de que este movimento tem de ser "preguiçoso" (i.é, tem de ser um movimento independentemente necessário para checagem de traços, o que segue da SDC). Esperaríamos, neste caso, que tanto (19b) quanto (20b) fossem estruturas bem-formadas: como vimos
antes, a especificação de Caso de objetos diretos é um traço de seu determinante e deve ser checado em $\mathrm{T}$; presumindo que [ki] seja um determinante interrogativo (como temos razões para presumir), ele então deve checar o traço de Caso de seu DP em T em frases como as de (19) e (20); portanto, o movimento atestado em (19b) e (20b) é um movimento "preguiçoso", i.é, de checagem de traços. No entanto, isto 
não é suficiente para assegurar a boa-formação de (19b) e (20b). Por quê? A resposta é: por causa de NO DELAY.

Como vimos, além do traço de Caso do objeto, [ki] tem pelo menos mais um traço formal a ser checado: o traço [+WH], que deve ser checado em COMP. Este traço pode ser checado após SPELLOUT, já que ele é fraco; para isso, entretanto, é preciso que [ki] satisfaça uma outra condição imposta por suas especificações lexicais: é preciso que haja, dentro de seu domínio prosódico, material fonético à sua direita ao qual possa se procliticizar (cf. discussão de (18) acima). Caso não haja tal material disponível, como em (19) e (20), [ki] deve mover-se pré-SPELL-OUT (ou a PF resultante não será convergente já que [ki] não estará procliticizado). Mas, se [ki] deve mover-se, então a condição NO DELAY em (10d) acima requer que a cadeia resultante seja máxima, i.é, NO DELAY requer que [ki] perfaça todas as operações de movimento necessárias para checar seus traços. Isto inclui não só a operação que leva [ki] até $T$, onde checa o traço de Caso do objeto, mas também e crucialmente a que o leva até COMP, onde deve checar seu traço [+WH].

Portanto, o efeito de NO DELAY é fazer com que, caso [ki] seja obrigado a mover-se pré-SPELL-OUT para procliticizar-se, ele deverá terminar seu movimento na posição apropriada para checar sua especificação [+WH], i. é, em COMP. É isso o que acontece em (19) e (20): em (19a) e (20a), [ki] está em COMP e satisfaz NO DELAY; em (19b) e (20b), [ki] não foi até COMP e viola, portanto, NO DELAY; por isso, (19b) e (20b) são excluídas.

Note agora que, se COMP não possui material lexical ao qual [ki] possa cliticizar-se, então, é necessário que a derivação torne este material disponível pré-SPELL-OUT, ou [ki] não será um proclítico e a PF não convergirá. Daí a necessidade de movimento de $[\mathrm{V}+\mathrm{T}]$ para COMP em (19a) e (20a): esta é a única operação de movimento que, sendo compatível com as demais condições gramaticais atuantes no contexto, torna material fonético ao qual [ki] pode se cliticizar disponível em COMP. Portanto, a inversão sujeito-verbo flexionado 
em (19a) e (20a) é uma operação de último recurso para salvar do fracasso em PF a derivação em que há movimento de [ki] ${ }^{11}$.

Em resumo, vimos nesta seção que é possível dar conta dos fatos fundamentais dos usos de [ki] como pronome e determinante interrogativo se:

(21) a.[ki] em PB é como a forma $o$ em PE, i.é, um determinante proclítico cujo traço de Caso é fraco (cf. (9) acima);

b. [ki] em PB difere de $o$ em PE pelo fato de ser também especificado para o traço $[+\mathrm{WH}]$, que tem de ser checado em COMP;

11 É possível, entretanto, que COMP seja preenchido por material lexical não derivado por movimento: como é sabido, há razões que indicam que COMP [+WH] pode ser lexicalizado como o complementizador que em PB (cf. MIOTO; FIGUEIREDO SILVA,1995, e referências lá citadas). Em tal situação, haveria conteúdo fonético independente em COMP ao qual [ki] poderia se procliticizar e, portanto, inversão sujeito-verbo flexionado não deveria ser necessária. $O$ fato, entretanto, é que a seqüência [ki]-que não nos soa apropriada senão com acento sobre [ki], em cujo caso a pronúncia preferida em nosso dialeto é [kê]:

(i) ??[ki]-que o João fez?

(ii) [kê]-que o João fez?

Este contraste talvez se explique pelo fato de que o complementizador ser necessariamente pronunciado como [ki] átono nestas frases. A Profa. Leda Bisol acredita, por outro lado, que ambos ques podem ser átonos se formam uma palavra fonológica com o sujeito. Estas, é claro, são questões que deveremos deixar em aberto aqui.

Observe-se também que há dialetos em que a inserção do complementizador que é obrigatória com o interrogativo que átono porque a inversão sujeito-verbo não está disponível (Carlos Mioto, comunicação pessoal).

Note-se, finalmente, que se o sujeito for topicalizado em (19b) e (20b), o que se pode identificar pela pausa entonacional entre o sujeito manifesto e o resto da frase, a ordem superficial será [SUJ [ki]-[V+T] ... ]; portanto, superficialmente, parecerá não ter havido inversão sujeito-verbo flexionado. Entretanto, é muito provável que, mesmo nestes casos, o complexo [ki]-[V+T] esteja de fato em COMP: como se sabe, tópicos ocupam uma posição linear que precede os elementos em COMP:

(iii) E a Maria, quando o João viu (ela)? 
c. as premissas minimalistas adotadas por Raposo (cf. (10) acima) estão corretas e são necessariamente complementadas por NO DELAY.

Evidentemente, a análise de [ki] em PB resumida em (21) é, no essencial, análoga à análise que Raposo propôs para a forma $o$ em PE; como procuramos mostrar, as diferenças entre $o$ e [ki] podem ser deduzidas naturalmente uma vez que se leva em conta (21b), que é uma afirmação independentemente estabelecida. Assim, podemos concluir que as propriedades de [ki] em PB reforçam a linha geral de análise sugerida por Raposo: pronomes podem ser, na verdade, determinantes, e as eventuais diferenças entre estes dois "usos" da categoria dos determinantes podem ser um mero reflexo da interação das condições de economia com as condições de convergência específicas a que diferentes tipos de derivação estão sujeitos.

Cabe, finalmente, notar que há um aspecto em que a análise acima proposta para [ki] em $\mathrm{PB}$ pode diferir da análise de $o$ em PE: como vimos, NO DELAY é necessária para dar conta do paradigma em envolvendo [ki] em (19)-(20), mas pode não ser necessária para dar conta do paradigma envolvendo a forma $o$ em (6) acima (ver discussão destes casos). Neste sentido, embora a distribuição da forma $o$ possa não oferecer motivação conclusiva para a necessidade de incorporar algo que tenha os efeitos expressos por NO DELAY, a distribuição de [ki] em PB certamente o faz.

Gostaríamos de encerrar este squib apontando brevemente alguns problemas empíricos e algumas questões teóricas postos pela análise que acabamos de apresentar nesta seção.

\section{Alguns problemas e questões}

Há pelo menos dois problemas empíricos a serem enfrentados por desenvolvimentos futuros da análise de que que propusemos na seção anterior. O primeiro deles diz respeito a uma diferença entre $o$ e que que não é explicada pelas hipóteses que adotamos. A diferença a que nos referimos é a seguinte: como vimos nas seções 1 e 2, a forma $o$ pode ocorrer na posição de determinante desde que haja material fonético dentro do DP, independentemente de que material seja este - i.é, não é necessário que haja um $\mathrm{N}$ com conteúdo fonético à sua direita, confira:

(22) Gostei de quase todos os carros que vi, ... 


\section{INTERROGATIVO QUEEM PORTUGUĖS BRASILEIRO}
a.mas só compraria $[o$ vermelho]
b.mas só compraria [o _ da Maria]
c.mas só compraria [o _ que Maria viu]

Como vemos, tais ocorrências da forma $o$ são relativamente fáceis de conceber. O mesmo não acontece com que (i.é, [ki]): contextos apropriados para o uso de $\mathrm{N}$ vazio acompanhado de que são difíceis de achar. Um deles, o contexto em (23) abaixo, impõe restrições: pode-se ter um $\mathrm{N}$ vazio acompanhado de que, mas só quando o modificador é um adjetivo:

(23) a. A: Gostei de quase todos os carros que vi, inclusive de alguns vermelhos...

B: [Quais/Que _ vermelhos]?

b. A: Gostei de quase todos os livros que li nas férias, inclusive de alguns da Maria...

B: [Quais/*Que __ da Maria]?

c. A: Gostei de quase todos os livros que li nas férias, inclusive os que a Maria indicou...

B: [Quais/*Que _ que a Maria indicou]?

Há um outro contexto em que que pode ser seguido de um adjetivo ou um PP; quanto a ser seguido por uma oração relativa, o resultado nos parece um pouco pior (talvez pelas razões discutidas na nota 11 acima):

(24) a. A: João, pega um dos copos verdes que estão aí dentro do armário.

B: [Que _ verdes (o quê)?!] Só vejo copos azuis aqui...

b. A: João, pega um desses livros do Guimarães Rosa que estão aí sobre a mesa.

B: [Que _ do Guimarães Rosa (o quê)?!] Só vejo livros do João Ubaldo aqui...

c. A: João, pega um desses livros que a Maria comprou.

B: ??[Que _ que Maria comprou (o quê)?!] Só vejo os livros que EU comprei aqui...

As restrições ilustradas em (23) e (24) não podem, evidentemente, ser explicadas como violações dos requisitos de convergência de que em PF. Não afetam, entretanto, o paralelo entre a forma $o$ e que que estabelecemos, já que a ocorrência ocasional de um 
$\mathrm{N}$ vazio com que (cf. (23a) e (24a,b)) demonstra que esta estrutura é possível também com que. Quanto às restrições que encontramos nos contextos em (23) e (24), acreditamos que possam ser derivadas de propriedades lexicais da forma que que a distinguem de $o$; discutir tal tópico, entretanto, esta aquém dos limites deste $s q u i b^{12}$.

Uma outra dificuldade empírica para a análise unificada que propusemos dos usos da forma que em PB reside na distinção entre o elemento clítico [ki] e seu alternante tônico [kê]: ambas manifestações de que podem ser usadas como pronomes interrogativos e estão regularmente associadas do ponto de vista fonológico (i.e., a forma [ki] é fonologicamente preditível de uma forma subjacente [ke] em contexto átono); isso evidentemente sugere que [ki] e [kê] são uma mesma forma e que, portanto, uma análise unificada de ambos é desejável. Do mesmo modo, a forma que que aparece no sintagma interrogativo o que também está não apenas associada as demais ocorrências de que interrogativo por sua função sintática, mas também é fonologicamente preditível: que em o que pode se manifestar como [kê] e, portanto, pode receber acento, porque forma uma palavra prosódica com o clítico $o$ (o mesmo sendo verdade para o pronome interrogativo que regido por preposições, como em para quê, de quê,

12 Apenas para ilustrar o tipo de abordagem que temos em mente, considere, p.ex., o fato de que que só pode ser usado com adjetivos em (23). Neste contexto, que alterna idiomaticamente com qual/quais, que não observa a mesma restrição. Por quê? A diferença básica entre que e qual/quais é que que não é especificado para traços- $\phi$ (mais especificamente, para número). Suponha que o $\mathrm{N}$ vazio em (23) requeira, para ser licenciado, que algum elemento do ambiente sintático seja especificado para traços- $\phi$. $\mathrm{Se}$ isso é verdade, este $\mathrm{N}$ vazio em (23) será licenciado com qual/quais independentemente do conteúdo existente dentro do DP. Com que, entretanto, o $\mathrm{N}$ vazio só será licenciado se houver algum outro elemento dentro do DP especificado para algum traço- $\phi$, já que que, ele mesmo, não possui tal especificação. Adjetivos são especificados para traços- $\phi$, mas PPs e orações relativas não; logo, acompanhado de que, o $\mathrm{N}$ vazio em (23) só poderá ocorrer se o modificador for um adjetivo. (Note que essa linha de raciocínio sugere que os Ns vazios de (23) e (24) são categorias vazias diferentes.) Para alguma discussão das diferenças entre que e qual/quais, ver Menuzzi (1994); para a relação entre traços- $\phi$ e elipse nominal, ver Lobeck (1993). 
etc.). Ou seja, idealmente, uma análise unificada das várias ocorrências da forma interrogativa que é desejável. Para isso, entretanto, teríamos de admitir que [ki] não é lexicalmente um proclítico (já que ambas as ocorrências acentuadas [kê] não são proclíticos) nem um determinante, mas um elemento não especificado para a distinção entre Ds e Ns (já que que em $o$ que ocupa uma posição de $\mathrm{N}$, e não de $\mathrm{D}$ ). É preciso, entretanto, demonstrar que, com tais premissas, poderíamos ainda preservar a análise que oferecemos das propriedades de [ki] na seção precedente, o que evidentemente não podemos fazer aqui.

Finalmente, gostaríamos de apontar algumas questões teóricas que emergem da análise que propusemos para as propriedades de [ki], mais especificamente quanto à necessidade de postularmos uma condição com os efeitos de NO DELAY. Como vimos, isto parece necessário para explicar porque o movimento parcial de [ki] não é suficiente para que a estrutura seja bem formada (cf. discussão do paradigma em (19)-(20)). Três questões surgem imediatamente no que diz respeito a NO DELAY: (i) há evidência adicional apontando para a necessidade desta condição (ou de que seus efeitos sejam, de algum modo, incorporados à teoria gramatical)? (ii) é NO DELAY uma condição primitiva, ou pode ser derivada de outras condições já disponíveis no aparato minimalista? (iii) como solucionar o conflito entre NO DELAY e PROCRASTINATE (cf. a discussão da nota 8 acima)? Obviamente, estas são questões que precisam ser investigadas a fim de que a análise de [ki] que apresentamos acima tenha caráter explanatório.

\section{Referências}

AMBAR, M. Para uma Sintaxe da Inversão Sujeito-Verbo em Português. Colibri: Lisboa, 1992.

CARVALHO, J. B. Phonological Conditions on Portuguese Clitic Placement. Linguistics, n. 27, p. 405-436, 1989.

CHOMSKY, N. The Minimalist Program. MIT Press: Cambridge, EUA, 1995. 
CHOMSKY, N. Minimalist Inquiries: the Framework. MIT Occasional Papers in Linguistics 15, MIT, Cambridge, EUA, 1998.

LOBECK, A. Strong Agreement and Identification: Evidence from Ellipsis in English. Linguistics, n. 31, p. 777-811, 1993.

MATTOSO CÂMARA JR., J. A Estrutura da Lingua Portuguesa. Rio de Janeiro: Vozes, 1970.

MENUZZI, S. M. Algumas Observações acerca do Movimento de Verbos em Questões WH do Português. Trad. de Fábio Lopes da Silva. Letras de Hoje, n. 29, v. 2, p. 85-108. Porto Alegre, RS: PUCRS, 1994.

MIOTO, C.; FIGUEIREDO SILVA, M. C. WH que = WH é que? DELTA, n. 11, v. 2, p. 301-311, 1995.

RAPOSO, E. P. Da Teoria de Princípios e Parâmetros ao Programa Minimalista: Algumas Idéias-Chave. Ms. A aparecer como a apresentação da tradução portuguesa do Programa Minimalista, 1998a.

RAPOSO, E. P. Determinantes e Pronomes em Português. Hand-out do curso ministrado na PUCRS. Porto Alegre, RS, ago., 1998b. 